\title{
Qubit Noise Non-ference: a conversation
}

Bryan Jacobs, Alec Hall, and Aaron Einbond

A precursor to the October 2013 Noise in and as Music symposium in Huddersfield, the Noise Non-ference was a March 2013 event in New York City organized by Qubit (Bryan Jacobs and Alec Hall) and Aaron Einbond that included concerts, installations, and articles printed in an accompanying book and program flyer. ${ }^{1}$ The three co-curators discuss the event and its relation to noise in and around New York.

\section{Curating Noise}

Aaron Einbond: What was the starting point for curating a Noise Nonference?

Bryan Jacobs: We wanted to take as many submissions as we could of people who thought that maybe they were doing something that had to do with noise. And then we would look at it and ask, "how is that noise?" If we could find our way into it, then that was a check in the inclusion box. If this person thinks they are doing noise, can we see it that way at all? Is it possible?

AE: We had two labels that we used from the start: both an "open call," and the word "curation." So there was both the idea that it was a self-defined or user-defined topic, but also that we had a role in helping define it further.

BJ: An important part of the curation, I think, is that we had pieces that were not dealing with the acoustic quality of noise but were actually more invested

1 For further reading and listening, see the Noise Non-ference website, last modified March 29, 2013, http://qubitmusic.com/2012-13season/. 
in the contextual idea of noise: noise only being called noise because of the context that it's in.

AE: In retrospect, sometimes those pieces that didn't meet the most obvious acoustic definitions of noise were those that I appreciated the most.

BJ: Right. It seemed ironic that a lot of the pieces that didn't have sonically noisy things going on seemed the noisiest.

Alec Hall: On that note, a fundamental aspect of the curation was the attempt to problematize the concert hall, the concert space, and the relationship between transmitter and receiver. As in the Jacques Rancière text The Emancipated Spectator, ${ }^{2}$ many of the pieces that we gravitated toward could offer some form of differing and empowering contributions, or else an experiential aspect for the audience that they could contextualize sociologically or philosophically as something noisy.

BJ: There is another definition of noise that, in retrospect, it seems like we avoided. I was never really interested in the idea of noise as random fluctuations or the non-meaningful part of a system.

AE: A few pieces came up that were somehow connected to that idea, like Richard Eigner's Denoising the Noise Non-ference, ${ }^{3}$ which has to do with the industry technique of removing noise. Although it's interesting that that particular example is a kind of negative. It's not about the noise itself, it's about the artifacts introduced into the signal that he's de-noising. Another example of digital noise was the junk mail that we received to the Gmail account, which was eventually included in the printed book. So in that sense

2 Jacques Rancière, The Emancipated Spectator, trans. Gregory Elliott (London: Verso, 2009).

3 Richard Eigner, "Denoising Project," accessed May 14, 2013, http://richard.ritornell.at/index. php?show=denoising. 
those junk mail submitters were actually noise artist participants, perhaps unintentionally.

AH: The preface to the spam collection in the Noise Non-ference book, which is somewhat truncated as there was much more that we didn't publish, says, "in the most extreme case, the communication mechanisms would sometimes transform submissions, with what we might call the intentionality of 'signal,' albeit with a noisy foreground, into 'noise' elements- unreadable documents that became a meta-narrative for the entire project." ${ }^{4}$ I'm thinking specifically of a submission where the PDF that we received was just a garbled array of symbols, the junky ends of a font. So that was a wonderful moment too: music — composed with noise in mind—which has already been passed through a filter, the "automagic" filter of the internet, arrives in our possession and then it is transformed yet again into something that is even noisier.

\section{Piano and Cardboard}

AE: Were there ideas of noise that we didn't have when we started that somebody suggested to us or became clear to us?

BJ: So many of them weren't what I was expecting, like the piece by Ian Power (Figure 1, Appendix, p.236) that started the whole festival. ${ }^{5}$ It was the only piece on the program that was noisy because of its length.

AE: If I remember from the curation process, we thought: "this could be noise, but we're going to let Ian go with his idea, to see if he can convince us." So that was a case of risk-taking. I didn't predict the Cage-like experience of that

4 Qubit, Noise, A Non-ference, program book, 2013.

5 Ian Power, composer's website, accessed May 14, 2013, http://ianpoweromg.tumblr.com/. 
piece, where the question of whether the audience was going to participate by moving around, whether they were going to take extreme positions next to the piano, or whether there was going to be encouragement for them to do so, became a significant part of the presentation.

AH: Megan Beugger's piece (Figure 2, see Appendix, p.237) is an interesting example, because it's a hyper-complex and meticulously notated score for cardboard box and two performers. ${ }^{6}$

AE: And cardboard on the one hand is the infiltration of the everyday, which we do associate with noise in the sense of Cage. But on the contrary cardboard isn't an everyday material that we usually think of as noisy.

AH: But at the same time it's been written in a very "composerly" fashion, where she doesn't leave anything to chance, but the materials themselves are unstable.

AE: I had an interesting conversation with Megan right after her performance about the performers' approaches to the aleatoric aspects in that piece. As you say, the response of the cardboard is unpredictable, and so the performers sometimes find themselves in physical situations, in bodily poses, that they weren't expecting because one of their implements would tear further through the cardboard than it had previously. And they have to work their way out of those situations. So there is noise as unpredictability involved in that piece as well; although I agree that, at the same time, Megan has a firm composerly hand and ear guiding how those situations arise and how the performers get out of them.

6 Megan Grace Beugger, Daring Doris for cardboard trifold, composed for the Crossfire Percussion Duo, accessed May 14, 2013, http://www.youtube.com/watch?v=mOwARO1fDoE. 


\section{Noise Directions}

AH: What I'm really excited about is which direction, or multiple directions, this phenomenon of noise music will take, because noise resists a singular, $a$ priori definition.

AE: Before we even began the call, there was a sense that this was a topic that applied to a lot of different music that we were hearing, that people we knew were working on, and indeed that we were working on. And so there was a feeling that noise, as something to describe different musics, or even different arts, is something that is taking on a broader and broader inclusiveness, where perhaps the term "noise music" once defined a narrower genre to some people. I agree that part of what we were doing was looking at the directions noise is headed, but I wonder if those directions are anywhere but singular.

BJ: One of the appealing parts of doing this event was that it seemed quite inclusive compared to the two other tracks from which this conference emerged. One is traditional academic conferences, which are usually very specific in their calls and are limited to particular industries or art fields. And then there's another track of noise festivals, which are in abundance all over the place: all over the US at least, and even in Europe. Whenever you see a noise festival, it's actually a counter to an academic festival, and its roots are in folk music or pop music or DIY culture. The interesting thing about the Non-ference was to propose a halfway point between both of those.

AE: We were conscious from the title "Non-ference" of trying to go beyond certain expectations of an academic conference. We have all been part of North American academic life, and we have all felt that some musical topics that we are interested in are under-represented in that scene. So this was partially trying to rectify that. But a noise event of the other type, the "hacker" type, is something that also might not be very inclusive. So I would like to think about some people who might fit more comfortably in an academic 
music festival as actually belonging to a noise world that isn't acknowledged by some other parts of the noise world. As I've been doing research for this discussion, I noticed that none of the books on noise I have encountered so far include Helmut Lachenmann in the table of contents. Isn't it interesting that noise music, as a phrase, is something that so far hasn't really opened its doors to certain kinds of acoustic instrumental music?

\section{Noise NY}

AE: Is there a New York noise scene, and did the Noise Non-ference represent a New York noise scene in any way?

BJ: Yes, there is a New York noise scene. It is long and complicated, and it has always been a divided thing. There is a long scene in New York coming from the punk movement, including noise more and more in popular music. New York might be unique in that regard: even for what is happening in the noise component of "experimental" or "avant-garde" contemporary music, it has always had as its starting point the "punk-ness" of New York.

AH: But I think it's important to problematize the notion of what constitutes a "scene." Scenes are fragmentary and based more on a constellation of connections. New York is one of the noisiest places I've ever experienced. It's been this way for a century or much longer, the sheer number of people jammed into such a tiny space, each striving to assert dominance, one way or the other. New York is about co-habitation but it's also about economy, industry. This is in New York's DNA, which is why punk is from New York, hip-hop is from New York.

When you're walking down the street and a car rolls by blasting music at a ridiculous volume, with such a tricked-out stereo in the car that the plastic components of both the speaker system and the vehicle itself are vibrating because of the bass response, then who is not in the noise scene? 
BJ: I think one particular thing about New York that heightened the influences of noise here is a dichotomy between "uptown schools" and "downtown schools." The uptown school was trying to refine itself, to distance itself from the city that Alec is talking about, and the downtown school was trying to integrate itself and be inspired by it.

AE: Although I am weary of the uses and misuses of those two terms, during my lifetime as a New Yorker the noise content of uptown and downtown has reversed axes. In the 90s when I started going to concerts, the situation was what Bryan just mentioned: people active in the uptown scene, the more university department focused scene, were interested in pitch and rhythm and an acoustic instrumental "bel canto" performance quality, while some downtown artists were doing more noisy things. Now, if one hears something with a high noise content one would possibly associate that more with the Columbia University music department. And if one heard something with pure harmonic pitch content, one might associate that more with Bang on a Can. So even those very problematic terms have shifted their meaning on noise.

AH: From an ethnographic point of view this is enormously important, because over the last 20 years what we've seen in New York City is the total consolidation of extreme wealth in lower Manhattan. With this incredible influx of capital downtown, the lived experience of the city is going to become inevitably different, and what people were embracing in the 1960s, 70s, and 80 s is now something that any artist would be running away from.

AE: Many of the people who are looking to Brooklyn now, the way some artists looked to downtown Manhattan in the past, also might well predict that in a few years, if not already, Brooklyn will have the same fate.

BJ: But if we're going to go talk about it in relation to the art that's happening, a community does have a lot to do with the art that's being made, but the 
community that people are turning to now is an international and online and transitory one. That is having more of an impact, and individual economies and geographies are having less of an impact. So everything that changes in New York, and is also changing in Berlin, is not making me think that it is going to make a huge change to the art right now, this time.

AH: Physical geographic communities are super-important. But at the same time New York is so large and so diffuse that what we attempted to do with the Non-ference was to propose a kind of a synthesis, the academic coupled with the experimental, because that's not a community right now. That doesn't really exist.

AE: But to take it more metaphorically, I wonder if the "New York-ness" of the Non-ference had something to do with this idea of a synthesis or a constellation. We were all surprised at the enthusiasm of the responses we got to the call for submissions, and one reason, no doubt, is that a lot of people wanted to come to New York, to be part of this momentary community, this instantaneous intersection of people of different interests. New York has that quality of attracting passers-through who want to join in that ongoing, infinite, international conversation. So in that way maybe New York is like a prototype of the internet: it's an online community before online meant telecommuting-when it meant flying in or taking the train in. The connection between uptown and downtown, Brooklyn and Manhattan, all is part of that constellation.

We've mentioned Cage a few times during this conversation, and he's yet another quintessential New Yorker. Did the punk noise scene feel a conscious debt to the Fluxus noise scene? It's interesting that all of these divergent noise streams passed through New York.

AH: One of the habitual features of New Yorkers of course is the inability to stop talking about New York, so let's stop talking about New York. 


\section{Noise-ism}

AE: Bryan brought up the term "avant-garde" a moment ago, and we're familiar with the claim that young composers don't seem to gravitate around a focused rubric, like spectralism, like experimentalism, like minimalism, the way that maybe we imagine a past generation did. So it seems like in the background of this conversation is a proposition that noise might be a topic that actually does unite young composers in a way that these other topics do not. It would be going too far to posit that there is a "noise-ism" at work, but nevertheless I think it does stem from our desire, the three of us, to find a common ground for conversation with other practitioners our age.

AH: These frequent-or intermittent-temperature takings can be important, and I have noticed a kind of gravitation of younger composers towards noisier elements. But we had already established previously in this conversation that there is no one noise, there is no one way of looking at it or defining it. Noise is an empowering and liberating attitude. To borrow from one of our former teachers, Tristan Murail, it's not a technique, it's not materials, it's an attitude toward things, and ultimately it's up to every individual's own complex subjectivity to decide how to engage it.

AE: I was talking to David Gutkin, our musicologist friend, after the event. He was talking about the micro-genre of Occupy Wall Street pieces, which includes my piece Resistance, ${ }^{7}$ Alec's ensemble/orchestra pieces our bodies will be our demand, ${ }^{8}$ and George Lewis, who himself did something related to protest recently.

AH: The student protests in Québec.

7 Aaron Einbond, composer's website, accessed May 14, 2013, http://aaroneinbond.wordpress.com/ projects/resistance/. See also Chapter 4 of this volume.

8 Alec Hall, composer's website accessed May 14, 2013, http://www.alechall.info/. 
AE: So it's not just Wall Street, but nevertheless there does seem to be a connection between noise and Occupy having happened in New York just a year before.

AH: Well I think that our generation is so scarred and traumatized by the horrors of neo-liberalism. Becoming adults, we're witnessing the world completely fall away from us, in terms of what opportunities are available. And this is a natural reaction: the sounds or the noises of Occupy are actually the utterances of our generation.

\section{Living and Theory}

AE: Alec, you included a quotation from the dOCUMENTA ${ }^{9}$ curator Carolyn Christov-Bakargiev both on the website and in the Non-ference book: "to explore commitment, matter, things, embodiment, and active living in connection with, yet not subordinated to, theory." How does that connection between living and theory in the non-sound-art world inform both the Non-ference and what we're thinking about in our music?

BJ: I feel in New York, at least at the moment, a strong "populist" approach that is both strong theoretically and conceptually, but never lets accessibility fall to the background. That comes out of maybe Warhol and Copland, and incorporates the strongest ideas of conceptual art. People are insistent on having both, and we hold that in the highest esteem.

AH: Well, Christov-Bakargiev is an American, which makes it all the more relevant to what you're saying, Bryan. My reaction — the reason I included this quotation, and why I was hoping to encapsulate the ethos of the Non-ference by it-was that "theory" is interesting because it can be both predictive and future-oriented, but it functions primarily as a reaction to extant structures.

9 dOCUMENTA(13) exhibition website, accessed May 6, 2013, http://d13.documenta.de/. 
Without these structures, theory couldn't operate. That said, I think theory is a tool that is fundamentally necessary to engage the conceptuality of our work and to point us in directions that are worth exploring, or to illuminate certain moments we notice in the vagaries of the quotidian and might be able to explain in a much deeper or interconnected way.

AE: Your two comments make me think of the great Feldman quotation where Stefan Wolpe asks him about the man on the street and he looks out the window and sees Jackson Pollock. ${ }^{10}$ Bryan is absolutely right that there is a New York, or even North American, preoccupation with the populous, whatever that might mean to different people at different times. But, at the same time, artists in those places often take that to esoteric theoretical extremes.

You know the Richard Taruskin theory that historical performance practice is contemporary performance practice. ${ }^{11}$ When people make a theory about how to perform past music, they are actually making a theory about how to perform their own music. We've been witnessing these past couple of years this incredible Cage centennial, this focus on Fluxus, this focus on Dada, all of these past streams of creativity which suddenly seem very present, and it seems like that's a statement about our own work and our own creative impulses. All of those past moments, from Russolo to Cage to now, seem to speak to us especially loudly in 2012 and 2013. Maybe we're not doing something new, but that says something important about us.

BJ: As you said earlier, the response to the submission process for this Nonference blew me away. I thought we would get people to submit things, but I didn't expect that we'd get submissions from all over the place: cultures I didn't know were so interested in the idea of noise, and had different perspectives

10 Morton Feldman, Give My Regards to Eighth Street: Collected Writings, ed. Bernard Harper Freidman (Exact Change, 2000), 186.

11 Richard Taruskin, "On Letting the Music Speak for Itself," in Text and Act (Oxford: Oxford University Press, 1995), 51-66. 
on it. That word really resonates right now. It resonates in pop circles, and it resonates in academic circles also. It's compelling. Why is it so compelling now?

AH: Because noise is a totally inclusive phenomenon. It doesn't turn anybody away. It opens the door for everyone, because by definition it cannot exclude. People today are looking for an empowerment, or a validation of their subjectivity. Look at what's en vogue. There was a hilarious New York Times article about the transformation of an "avowed Manhattanite" into a Brooklyn Hipster. ${ }^{12}$ He goes to Brooklyn, to Williamsburg of course, and rents a hotel room in the Wyatt Hotel for a few nights. He takes a butchering knife skills class, gets a fixed-gear bike, a $\$ 200$ flannel shirt, and then it's all about DIY culture: pickling your own vegetables, killing your own animals, and creating a sense of self-reliance and "opting out." It's a return in a twisted sense to the counterculture of the 1960s of "dropping out," where one would make an affirmative statement of rebellious individuality because of how oppressive the social norms were. Unfortunately today we're simply opting out of consumer mass-production norms. People are looking for something with which to validate themselves in the face of an otherwise totally oppressive state regime, which is now the real result of the globalization of the 1990s. It is the internationalization of this kind of political superstructure that crushes the individual's ability to affirm his or her interiority. Every country in the West has essentially become the same place.

\section{Inclusion and Transgression}

AE: Alec, you just made a statement about the inclusiveness of noise, but of course in some cultures, in some moments, noise has been something identified with transgression, or protest. In the particular context of the

12 Henry Alford, "How I Became a Hipster," New York Times, May 1, 2013. 
Noise Non-ference, there was an open, welcoming atmosphere, not just in the curation process but in the event itself, in the way people wanted to share, to listen, to discuss what they were doing. Does that mean the noise loses its impact?

AH: Until the larger power structures are addressed, noise is still going to be transgressive. It's just a further opening up of the communities in which we live. To go back to George Lewis, during one of the University Lectures at Columbia he gave in 2011, which was inspirational for a piece I wrote called Striped Noise, he demonstrated a recording of the sounds of protesters at the Wisconsin State Capitol. To the protestors this ebullient celebration of shouting and banging pots and pans, making noise to be disruptive, was something that they were celebrating, whereas to the lawmakers it was something absolutely terrifying, or angering. So noise has this possibility that the relationship between the transmitter or the receiver is so vastly different. And it's a question not of whose side are you on, but how can you perceive it.

AE: Another question is, by putting lots of noisy pieces together in one place, how does their function change from when they might previously have been programmed in the middle of a concert, with some other kinds of music, for example, or played over a radio, or put into a different format?

BJ: Well, I think the most important thing was that the communal aspect that it had around it wouldn't necessarily be the same if it was played in a more traditional concert hall setting. I thought that was one of the good points of the whole Non-ference also. Everything was a bit lighter, wasn't it?

AH: Because people went there with an expectation to put on a different pair of ears, the selection of pieces-all of which had something to do with each other in one way or another-invited the audience members to participate in a very different kind of experience than if they had heard them as singular 
entities in a different context of more pitch-based music. Maybe you lose the transgressive edge, and maybe that's a good thing. Because if the only thing that stands out is that that piece was "out there," then we lose the ability to go further into the work and its more nuanced qualities. Maybe it's really saying something that we wouldn't have heard otherwise.

AE: I agree with that. By not submitting the audience to aggression through the unexpected-by instead welcoming them in-we're inviting them to come in to explore what's inside the noise of these pieces.

BJ: I do think about what other pieces are going to be on the program when I write music; often it will only be played one time anyway, so I know the other pieces that are going to be there. And I do like the interaction between my music and the other pieces that are on the program, but it does seem a little shallow to me, after a while, if the core response is of the piece being drastically different from everything else. Sometimes my piece is the loudest piece on the concert, and I did enjoy that response for a while, but maybe it's time to have it in a more critical context, to have all these pieces in more critical contexts.

AE: It's as if the act of curation became a kind of creative act of putting our work as composers in a context where it could be heard more clearly.

\section{What is Noise Music?}

AE: I want to end by asking both of you, and maybe myself: what is noise music, and why do you make it?

BJ: I actually never thought that I was making anything like noise music before the idea of doing a Non-ference was proposed. Then I started to try to re-evaluate my work to see if it does have much to do with noise. And I guess 
my part of the noise was maybe the contextual component of it. Sometimes that turns out to be sonically noisier, sometimes it doesn't, but I am interested in that idea of finding whatever the context is-either for that piece, or for that concert situation-and dealing with the component that's not supposed to be there. But it's just enough "not supposed to be there" for it to be peculiar. So I still don't know if you really call that noise or not, but it has something to do with the contextual outlier idea of noise.

AH: When I was at U.C. San Diego I was particularly interested in microtonality, and I made that a focus, and then ran into a dead end. I'm interested in the theoretical frameworks of this pitch space level, but it doesn't necessarily give me any kind of musical direction. And then when I moved to New York, I was fascinated with all the things that were going on around me: the sounds, the noises (those words are interchangeable). And there was a history of that in the city, with Robert Rauschenberg, for example, finding discarded objects and including them in canvases in his Combine paintings. Conceptually for me that was incredibly strong, and it meant that I could really experiment and I didn't need to worry about a style or pitch content. I could get the pitches from spectral analysis, and then in a way the music just wrote itself. It was totally engaging for me. So now, what's interesting to me is this Russolo and Cageian sense of understanding the world around us from the perspective of sound. There are limitless possibilities of what we could do with it, whether we choose to compose with it or not. And I think that there is no crisis in New Music, if you look at it that way, because we could go in any possible direction.

AE: It's interesting that you brought up expression. I have the same experience that when I was a student I somehow had received the message that my job as a composer was to express myself, and that led to a dead end at some point. For me the solution was to realize that, rather than trying to express myself, what I wanted to express was everything that I heard around me. 
AH: And your relationship to that.

AE: And by doing that, what music would end up, I found, was much more personal because of the way that my ear and my brain filters all of that information.

BJ: That's kind of crazy for both of you, that you find it way more personal to take as your starting point things that you didn't do anything about for their existence. The found sound as being a thing that is more expressive for you than something that you would create, say, out of a group of pitches or something like that, where you would think about every single pitch and it doesn't exist before you write it on the page.

AH: But at the same time, I understand the sentiment or the logic behind that statement when I hear someone saying, "I'm composing at the piano." What's the difference between the found sound objects that I got underneath the 1 train viaduct at 125 th Street versus a key that you hit on a piano or a note that you plucked on a violin, or any of these things that are more known to us and everybody else, than any of these sounds that Aaron and I are working with?

BJ: And to tear my statement apart on another level, when you do write notes on a page you're certainly thinking of how that music is in a tradition, whether you know it or not. So you're referring to all of these other pieces, all this other culture, that led to music of notes on a page. And that's even more prescriptive than found sound, arguably.

AE: Isn't it Ravel who said, if you don't compose at the piano you can only write chords you've already heard? ${ }^{13}$ Ravel is using composing at the piano to

13 “Comment sans piano ... pouvez vous trouvez des harmonies nouvelles?" Ravel quoted in Edward Lockspeiser, Debussy: His Life and Mind (Cambridge: Cambridge University Press, 1978), 59. 
make the opposite point that Alec just did. For Ravel, at a very different time and place, the piano was an experimental tool, a bit like a field recorder. The piano was a machine where he could test unheard sounds and think about his creative response to them.

So, it's not the material itself that helps me be more myself, it's actually this empirical point of view. It's the feeling that I can be more of a complete creative person when I react to the world around me by this kind of measurement or cataloguing.

AH: We learned the lessons from Cage, Stockhausen, and Xenakis in the sense of aleatoric, serial, or stochastic processes. Today nobody composes with any of that in mind; it's as if it happened and then it became a tool. It was used, it was exhausted, and now it's irrelevant. But when you deal with sound sources or noise sources—-found sound objects— there are elements of all of those mid-century practices at work. 